ÉẼSTI NSS TÉADUSTE AKADÉEMIÁ TOIMETISED. KÊEMIÁ

ИЗВЕСТИЯ АКАДЕМИИ НАУК ЭСТОНСКОИ ССР. ХИМИЯ

PROCEEDINGS OF THE ACADEMY OF SCIENCES OF THE ESTONIAN SSR. CHEMISTRY

$1988,37,3$

УДК 553.983.66.092.18

Лиа НАППА, $\overline{\text { Н. КЛЕСМЕНТ }}$. Наталья ВННК

\title{
ИССЛЕДОВАНИЕ СУЗАКСКИХ ГОРЮЧИХ СЛАНЦЕВ УЗБЕКИСТАНА МЕТОДАМИ ГИДРОГЕНИЗАЦИИ И КОНВЕРСИИ
}

В настоящей работе, которая является продолжением комплексного исследования нижнеэоценовых горючих сланцев Узбекистана $\left[{ }^{1-2}\right]$, приводятся результаты исследования сузакских сланцев методами гидрогенизации, конверсии и ожижения. Исследованные пробы отобраны в Бухаро-Каршинском районе, приуроченном к бортовой части Амударьинской впадины. Подробное описание залегания сланцев и геологическая характеристика приведены в [']. Были исследованы четыре пробы сланца, три взяты из Караунской скважины и четвертая из скважины Южный Хатар (табл. 1).

Таблица 1

Геологическая характеристика сузакских горючих сланцев [']

\begin{tabular}{|c|c|c|c|}
\hline $\begin{array}{l}\text { Номер } \\
\text { образца }\end{array}$ & Скважина & $\begin{array}{c}\text { Глубина отбора проб, } \\
\text { м }\end{array}$ & Описание \\
\hline
\end{tabular}

109

Южный Хатар скв. 3

151

Караунская, скв. 11

154 155

$362,15-362,20$
$362,10-362,15$

черный сланец с включениями раковин фораминифер и крупной чешуи рыб

тонкое переслаивание горючего сланца и серого аргиллита с ходами илоедов

черный сланец с обломками фосфатизированных костей

\section{Экспериментальная часть}

Все опыты проводили в качающемся 0,4-литровом автоклаве. Температура опытов $380^{\circ} \mathrm{C}$, время 3 ч. Соотношение сланец : бензол составляло $1: 10$, т.е. 20 г сланца и 200 мл бензола (10\%-ный водный раствор $\mathrm{NaOH})$. Применяли пробы сланца после выделения битумоидов А и С. Характеристика исследуемых проб приведена в табл. 2.

Таблица 2

Характеристика дебитумоидированных проб сузакских сланцев

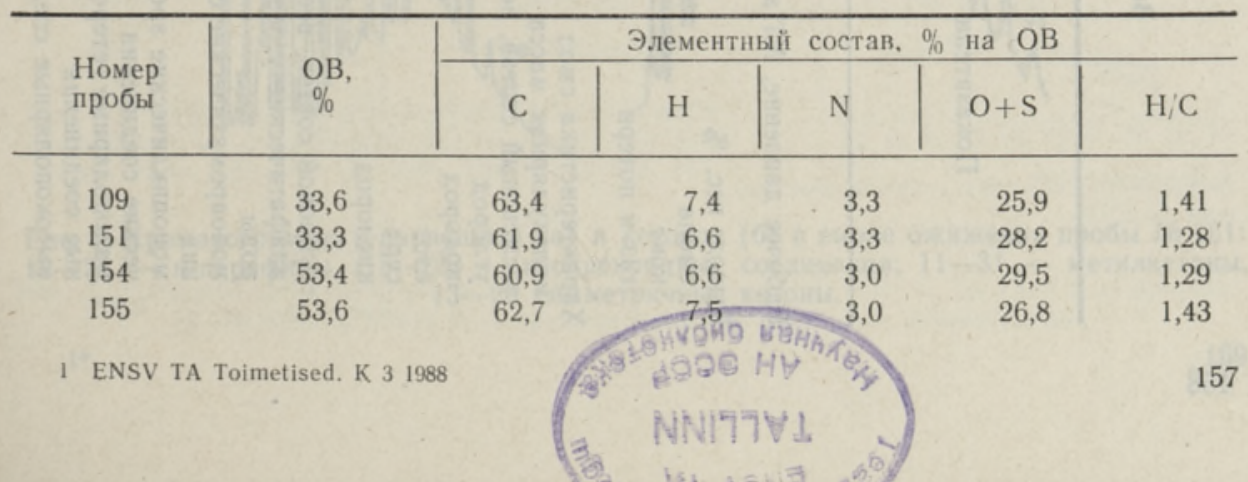




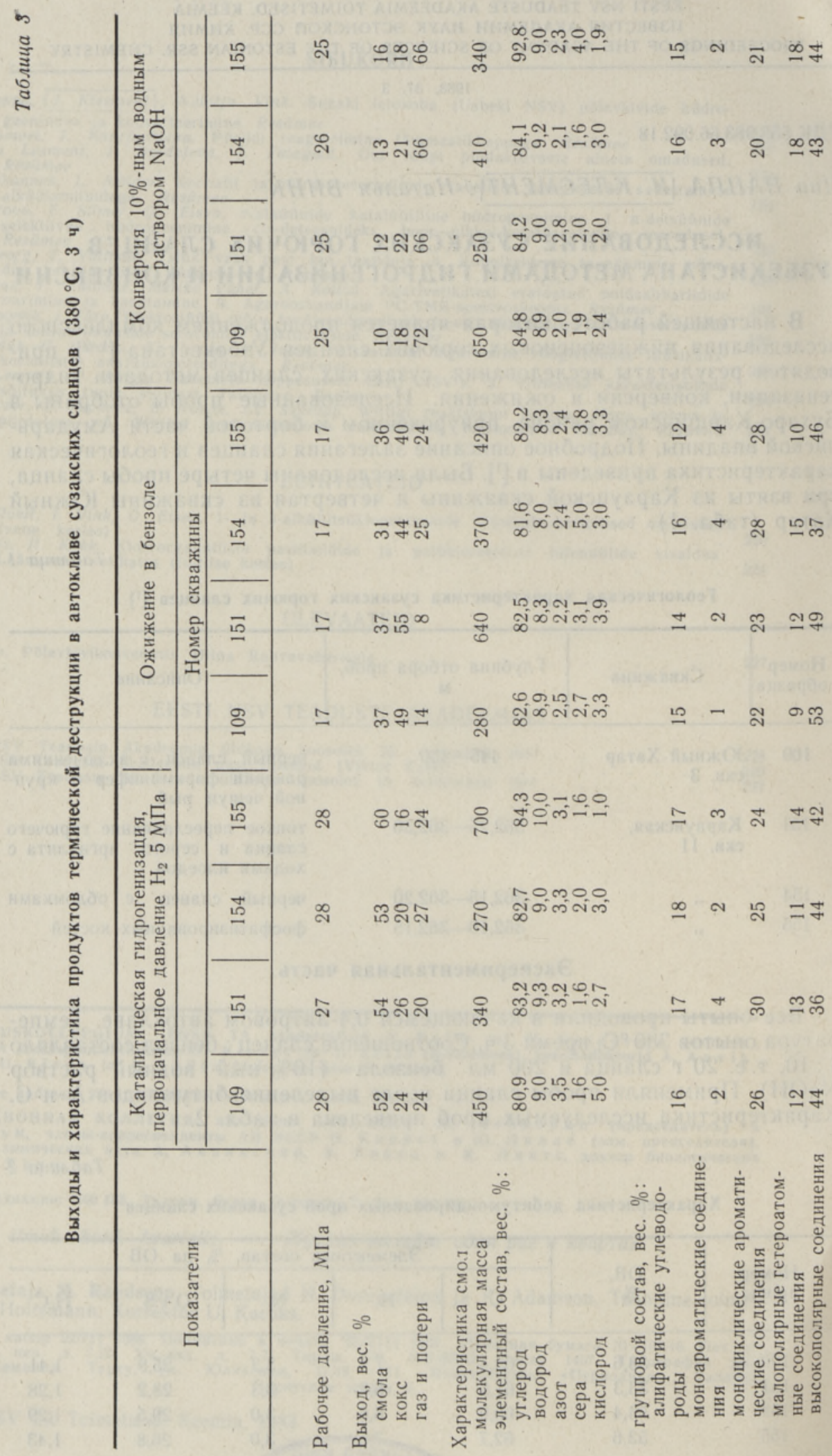


Б̈ыли проведены следующие опыты:

1. Гидрогенизация, первоначальное давление водорода 5 М̈П̈а:: а) катализатор молибдат аммония, из расчета $1 ; \%$ Мо на ОВ, б) без катализатора.

2. Ожижение в бензоле.

3. Конверсия $10 \%$-ным водным раствором $\mathrm{NaOH}$.

Образовавшиеся жидкие продукты реакции отделяли от нерастворимого остатка фильтрованием и разделяли на группы еоединений методом препаративной тонкослойной хроматографии на силікагеле [ $\left.{ }^{3}\right]$. Суммарные смолы и разделенные фракции анализирөвали газохроматографически на приборе «Хром-4». Компонентный состав газа исследова̀ли на хроматографе УХ-2. ИК-спектры снимали на спектрофотометре UR-10 в таблетках из $\mathrm{KBr}$.

\section{Обсуждение результатов}

Данные о выходе и характеристике продуктов деструкции приведены в табл. 3. Самые высокие выходы смолы из сузакских сланцев получаются при дополнительном введении в процесс водорода. Аналогичное явление имело место и при изучении других сланцев [ ${ }^{4,5}$. Конверсия $10 \%$-ным водным раствором щелочи дает самый низкий выход смолы -.. $19-24 \%$ от выхода, полученного при гидрогенизации, что даже ниже выхода смолы полукоксования, который для данных проб составляет от

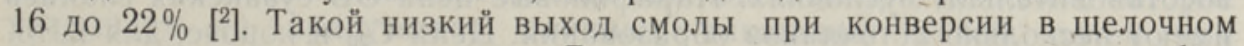
растворе отмечен нами впервые. В предыдущих исследованиях с прибавлением щелочи к воде выход смолы обычно повышался до выхода, полученного при полукоксовании, иногда и выше [4, 5]. По-видимому, механизм деструкции с участием воды существенно зависит от состава органического вещества $(\mathrm{OB})$ и минеральной части сланца.

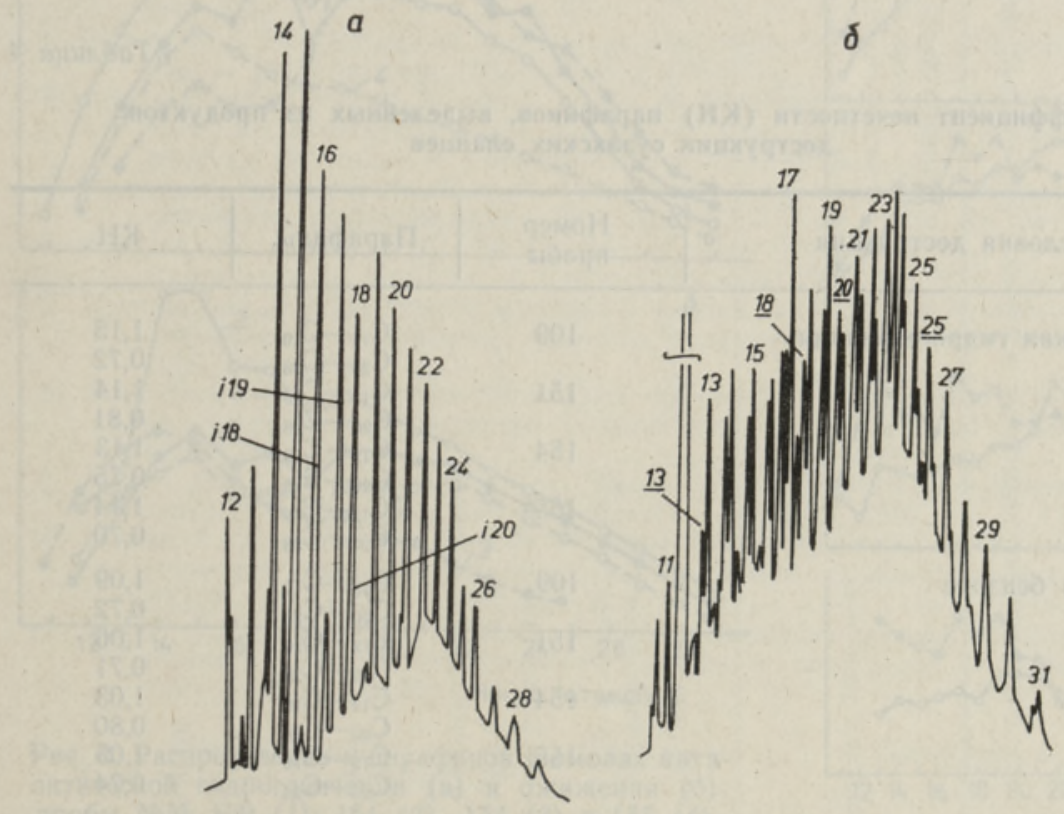

Рис. 1. Хроматограммы $12-28-н$-парафины, $i 18-i 20-$ изопренондные соедннения; $11-31-$ метилкетоны, 13 - 25 симметричные кетоны. 
К̆личество образующегося газа при каталитической гидрогеeниза̀ции и ожижении не превышает $20-27 \%$, тогда как при конверсии оно возрастает до двух третих от ОВ. Основными компонентами газа являются метан и двуокись углерода. Групповой состав смол гидрогенизации и конверсии четырех проб довольно близок. Смолы содержат как ароматические, так и алифатические соединения.

Хроматографический анализ показывает, что в смолах сузакских сланцев алифатические соединения $\mathrm{C}_{12}$ до $\mathrm{C}_{31}$. Значительная доля приходится на изопреноиды от $i \mathrm{C}_{18}$ до $i \mathrm{C}_{20}$ (рис. 1 , а). Особенно высока концентрация $i \mathrm{C}_{19}$-пристана, в некоторых смолах ожижения она даже выше концентрации рядом стоящего парафина $\mathrm{C}_{17}$. Этот факт указывает на окислительные условия процесса образования сузакских сланцев и на -то, что они не подвергались действию высокой температуры. Подсчитан коэффициент нечетности $(\mathrm{KH})$ [ $^{6}$ парафинов в пределах $\mathrm{C}_{12}-\mathrm{C}_{19}$ и $\mathrm{C}_{20}-\mathrm{C}_{28}$ (табл. 4). У парафинов в пределах $\mathrm{C}_{12}-\mathrm{C}_{19}$ наблюдается несколько повышенная концентрация нечетных гомологов (KН 1,03-1,15), что указывает на их биологнческое происхождение, тогда как в пределах $\mathrm{C}_{20}-\mathrm{C}_{28} \mathrm{KH}$ меньше единицы $(0,70-0,83)$. Преобладание четных гомологов парафинов в пределах $\mathrm{C}_{21}-\mathrm{C}_{29}$ было нами установлено и в смолах термической деструкции ОВ сысольского сланца [4], однако это явление в случае геолипидов встречается редко и считается признаком генезиса отложений в сильно восстановительных условиях. Парафиновые цепп ОВ сузакских сланцев имеют несколько источников образования. Цепи $\mathrm{C}_{20}$ и короче, для которых характерен повышенный $\mathrm{KH}$, имеют морское происхождение, а более длинные парафиновые цепи образовались из наземного бактериально переработанного материала. КН является показателем сохранности фрагментов исходного биологического вещества (жирных кислот) в структуре керогена. В ходе керогенообразования кислоты с четным числом углеродных атомов декарбоксилируются [7], образующиеся в процессе деструкции парафины имеют обычно нечетное число атомов угле-

Таблица 4

Коэффициент нечетности (КН) парафинов, выделенных из продуктов деструкции сузакских сланцев

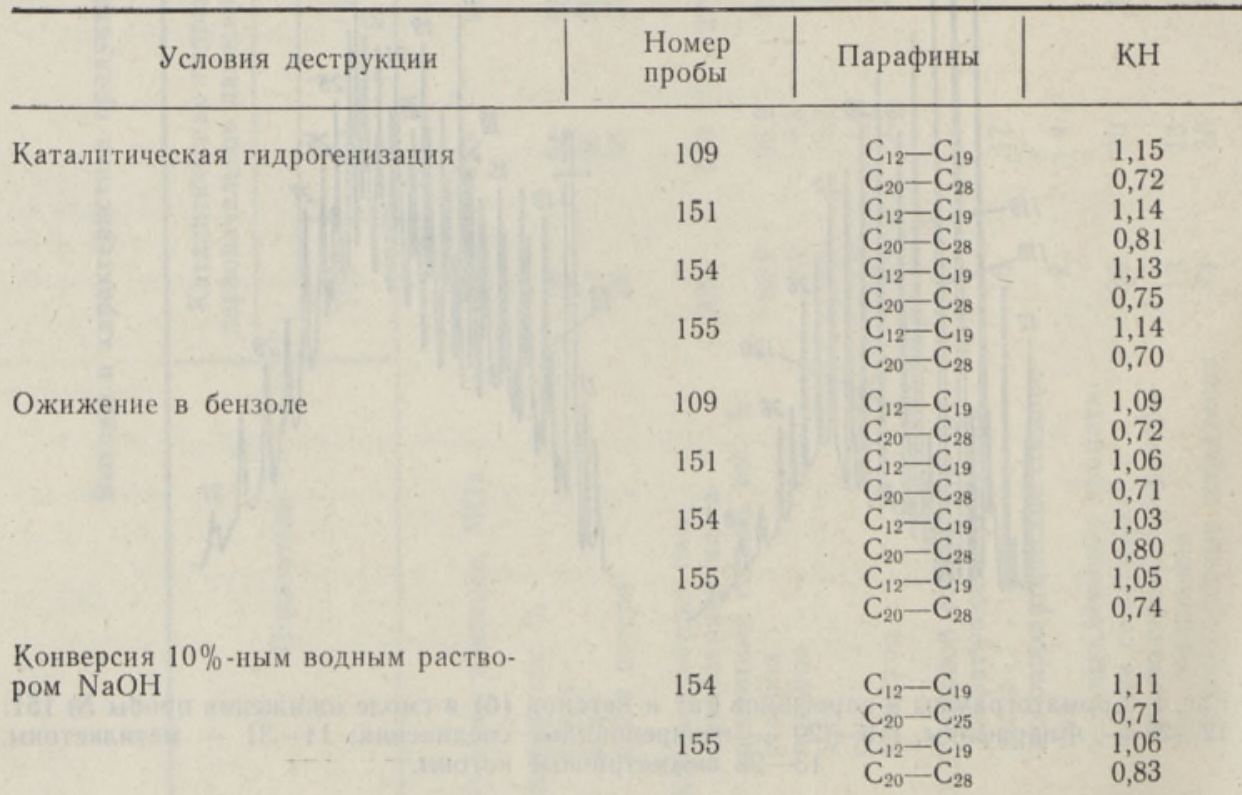


рода $\left[{ }^{8}\right]$. Из распределения $\boldsymbol{H}$-парафинов в смолах, полученных каталитической гидрогенизацией и ожижением (рис. 2), видно, что в пределах $\mathrm{C}_{12}-\mathrm{C}_{19}$ доминируют нечетные, а в пределах $\mathrm{C}_{20}-\mathrm{C}_{28}$ - четные парафины.

Ароматические углеводороды представлены в бсновном гомологами нафталина. Особый интерес представляет группа малополярных гетероатомных соединений смолы, содержащих кислород. На хроматограмме смолы ожижения (рис. 1,б) видны пики, принадлежащие гомологическому ряду $н$-алканонов от $\mathrm{C}_{11}$ до $\mathrm{C}_{31}$. Идентифицированы как метилкетоны, так и кетоны с центральным расположением карбонильной группы. Неожиданно много образовалось кетонов при ожижении сузакских сланцев в среде бензола. Во всех предыдущих исследованиях ОВ горючих сланцев разных месторождений образование значительных количеств кетонов в основном происходило при водной конверсии. До $\mathrm{C}_{20}$ $\left(\mathrm{C}_{22}\right)$ доминируют метилкетоны (рис. 3$)$, а начиная с $\mathrm{C}_{21}\left(\mathrm{C}_{23}\right)$, наоборот, преобладают кетоны с карбонильной группой в середине цепи. Из рис. 3 видно, что концентрация кетонов с нечетным числом атомов углерода выше четных гомологов. Особенно высокую концентрацию имеют $\mathrm{C}_{17}, \mathrm{C}_{19}$ и $\mathrm{C}_{21}\left(\mathrm{C}_{23}\right)$.

ИК-спектроскопические исследования показали, что во всех смолах термической деструкции выражено поглощение $3500-3200 \mathrm{~cm}^{-1}$, соответствующее валентному колебанию Н-связи в -ОН-группах. Максимальное поглощение во всех смолах наблюдается при $1470 \mathrm{~cm}^{-1}$, которое указывает на присутствие длинных алкановых цепей, затем при $1380 \mathrm{~cm}^{-1}$ (метиловые группы) и $1700 \mathrm{~cm}^{-1}$ (карбонильные группы).
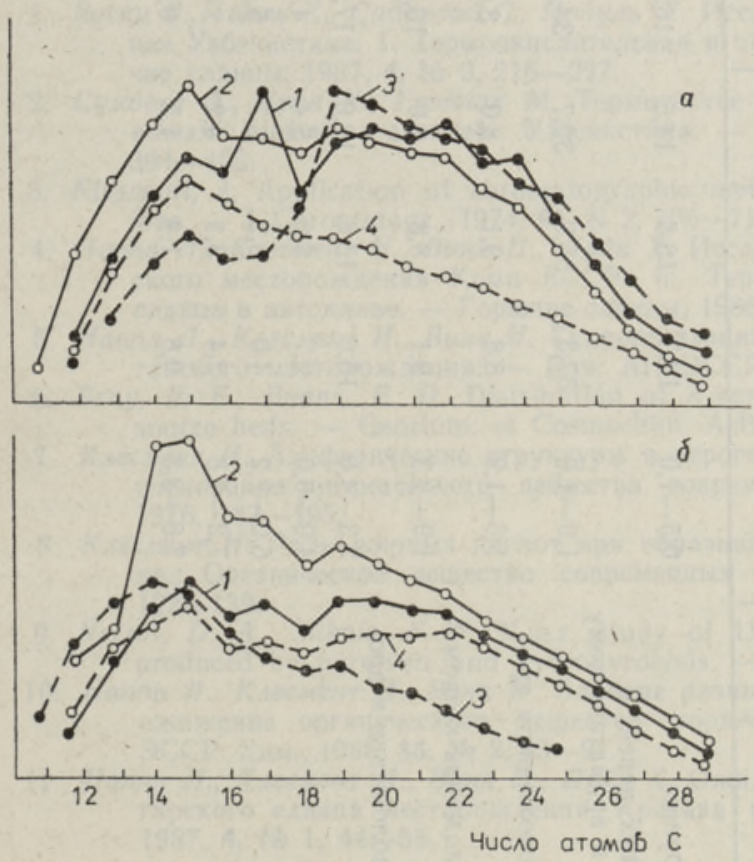

Рис. 2. Распределение $н$-парафинов в смолах каталитической гидрогенизации (а) и ожижения (б): пробы №o 109 (1), 151 (2), 154 (3) и 155 (4).
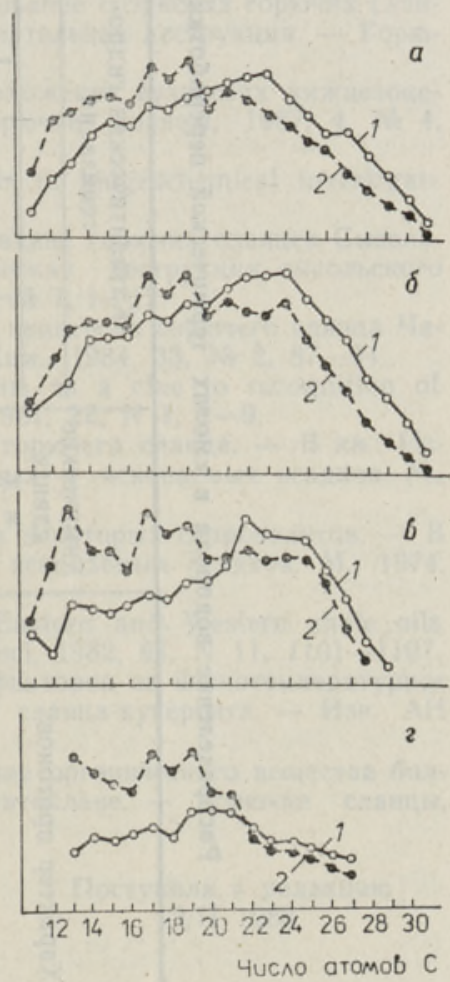

Рис. 3. Распределение кетонов в смолах ожижения (а, № 109; б, № 151) и конверсии (в, № $154 ; \mathrm{r}, 155): 1$ - снмметричные кетоны, 2 - метилкетоны. 


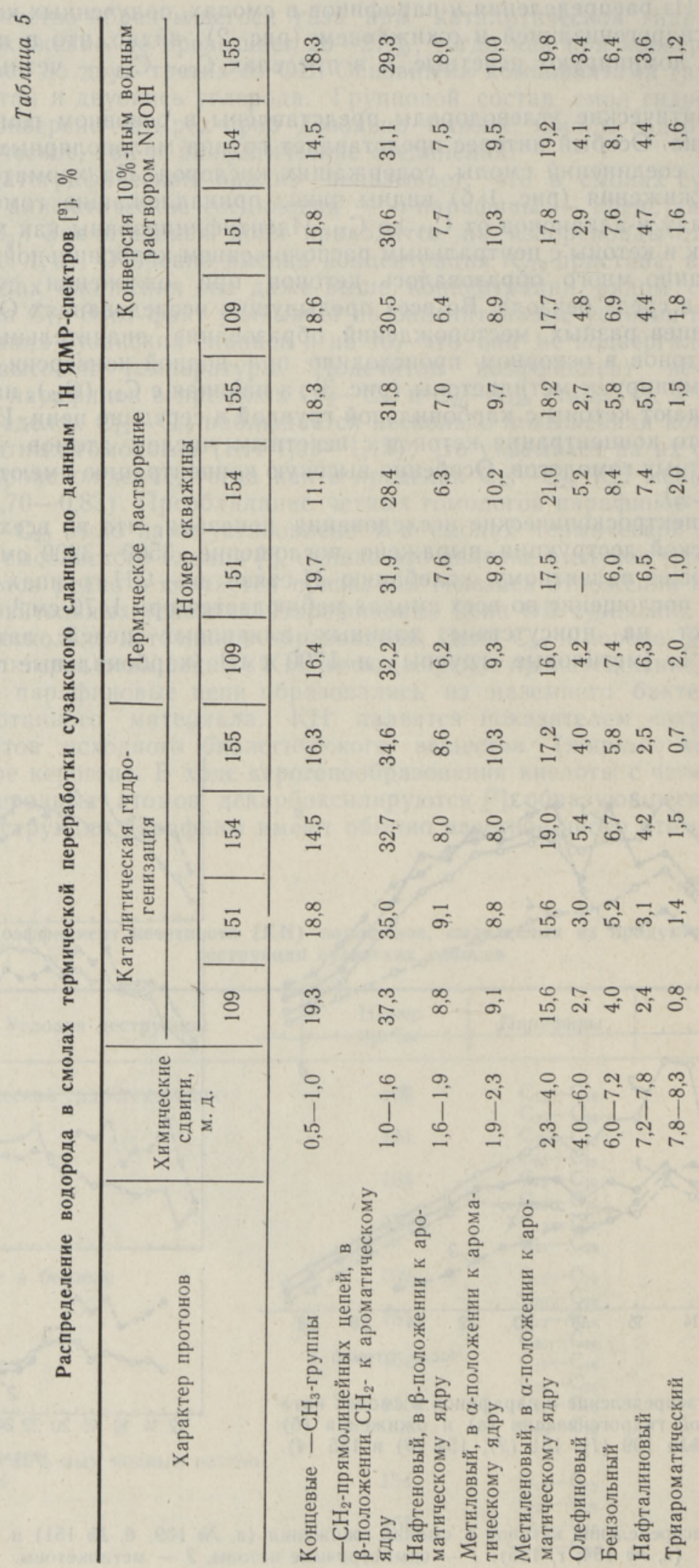


Поглощение ароматических - $\mathrm{CH}$-групп (3050 и $\left.3020 \mathrm{~cm}^{-1}\right)$ относительно низкое. Поглощение при $1600 \mathrm{~cm}^{-1}$ (валентное колебание бензольного кольца) ярко выражено в смолах конверсии, тогда как в смолах ожижения и гидрогенизатах оно более слабое, такая же картина поглощения имеет место при 745 и $720 \mathrm{~cm}^{-1}$. Данные ИК-спектров совпадают с данными группового состава, по которым видно, что смолы содержат ароматические и алифатические соединения в более или менее одинаковых количествах. Из данных ${ }^{1} \mathrm{H}$ ЯМР-спектров (табл. 5) видно, что основная часть водорода $(28-37 \%)$ во всех смолах представлена метиленовыт в прямолинейных цепях алканов, находящихся в $\beta$-положении и дальше от ароматического ядра $(1,0-1,6$ м. д.). Такое же распределение водорода имели и ранее изученные сланцы $\left.{ }^{4,5}\right]$. В метиленовой группе, связанной с ароматическим ядром в $\alpha$ - положении, содержится от 16 до $21 \%$ водорода; на водород, находящийся в группах, связанных с ароматическими ядрами (одно-, двух-и триядерной ароматики), приходится от 9 до $17 \%$, это значительно выше, чем в других ранее изученных сланцах, например в кукерсите $\left[{ }^{10}\right]$ и в сланцах месторождений Сысола [4] и Красава [11].

Суммируя, можно сказать, что в результате высокого содержания гетероэлементов в ОВ высокие выходы смолы при ожижении получаются лишь при дополнительном введении в процесс водорода. Впервые обнаружены нами кетоны в процессе ожижения в среде бензола. Содержание серы снижается при термической деструкции, особенно при каталитической гидрогенизации и конверсии в щелочном растворе.

\section{ЛИТЕРАТУРА}

1. Вески P., Тааль X., Сидорова С., Побуль Л. Исследование сузакских горючих сланцев Узбекистана. 1. Термоокислительная и окислительная деструкция. - Горючие сланщы, 1987, 4, № 3, 216-227.

2. Сумберг A., Уров K., Гринчак M. Термическое разложение сузакских нижнеэоценовых горючих сланцев Узбекистана. - Горючие сланцы, 1987, 4, № 4, $394-403$

3. Klesment, I. Application of chromatographic methods in biogeochemical investigations. - J. Chromatogr., 1974, 91, N 2, 705-713.

4. Напnа Л., Клесмент Н., Винк Н., Луйк Х. Исследование горючих сланцев Сысольского месторождения Коми АССР. 6. Термнческая деструкция сысольского сланца в автоклаве. - Горючие сланцы, 1986, 3, № 1, 1-12.

5. Напnа Л., Клесмент Н., Винк Н. Гидрогенизащия и конверсия горючего сланща Чаганского месторождения. - Изв. АН ЭССР. Хим., 1984 33, № 2, 87-94.

6. Bray, E. E., Evans, E. D. Distribution of $n$-paraffins as a clue to recognition of source beds. - Geochim. et Cosmochim. Acta, 1961, 22, N 1, 2-9.

7. Клесмент Н. Алифатические структуры в керогене горючего сланца. - В кн.: Исследование органического вещества современных и ископаемых осадков. М., $1976,187-195$.

8. Клесмент И. Роль жирных кислот при образовании некоторых сапропелитов. - В кн.: Органическое вещество современных и ископаемых осадков. М., 1974, $122-129$.

9. Netzel, D. A., Miknis, F. P. N.m.r. study of US Eastern and Western shale oils produced by pyrolysis and hydropyrolysis. - Fuel, 1982, 61, N 11, 1101-1107.

10. Hanna Л., Клесмент Н., Винк Н. Влияние разных факторов на низкотемпературное ожижение органического вещества горючего сланца-кукерсита. - Изв. АН ЭССР. Хим., 1986, 35, № 2, 83-91.

11. Напnа Л., Клесмент И., Винк Н., Луйк Х. Ожижение органического вещества болгарского сланца месторождения Красава в автоклаве. - Горючие сланцы, 1987,4 , № $1,44-55$.
Ннститут химии
Академии наук Эстонской ССР
Поступила в редакцию 12/II 1988 


\section{SUZAKI LEIUKOHA (USBEKI NSV) PŌLEVKIVIDE HODROGEENIMINE JA KONVERTEERIMINE}

On uuritud Buhhaara-Karši rajoonist Suzaki leiukohast võetud nelja põlevkiviproovi hüdrogeenimisel, veega konverteerimisel ja termilisel lahustamisel autoklaavis ning kindlaks tehtud, et lisavesiniku sisseviimisel autoklaavi suureneb hüdrogeenimisel saadava ôli saagis ligi kolm korda, s. o. kuni $52-60 \%$-ni võrreldes poolkoksistusōli saagisega, mis on $\left.16-22 \%{ }^{2}\right]$. Termilisel lahustamisel on ôli saagis $34-37 \%$, konverteerimisel leelisvesilahu keskkonnas aga ainult $10-16 \%$.

Olide alifaatsed ühendid on esindatud $n$-parafiinidega $\mathrm{C}_{12}-\mathrm{C}_{31}$, oluline on isoprenoidsete süsivesinike $i \mathrm{C}_{18}-i \mathrm{C}_{20}$ osa. Aromaatsetest ühenditest on identifitseeritud pōhiliselt naftaliini homoloogid. Erilist huvi pakuvad autoklaavtöötlusel saadud ōlide vähepolaarsed, hapnikku sisaldavad heteroühendid - metüülketoonid ja ketoonid, kus karbonüülrühm on tsentraalasendis $\mathrm{C}_{11}-\mathrm{C}_{31}$. On täheldatud ketoonide teket lisaks konverteerimisprotsessile ka termilisel lahustamisel benseenis. Autoklaavtöötlusel saadud ólides, eriti hüdrogeenimisel saadutes, alanes väävlisisaldus vôrreldes poolkoksistusōliga.

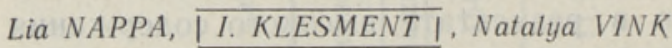

\section{HYDROGENATION AND CONVERSION OF THE SUZAK OIL SHALE OF THE UZBEK SSR}

Results of destructive decomposition in autoclave - hydrogenation, liquefaction and conversion of four oil shale samples of the Bukhara Karshi region are discussed. The yields of thermal destructive products depend on the destruction method. The highest oil yield was obtained by hydrogenation at an initial hydrogen pressure of $5 \mathrm{MPa}-$ it is 3 times more $(52-60 \%)$ in comparison with the oil yield obtained by semi-coking $\left(16-22 \%\left[{ }^{2}\right]\right)$. By liquefaction the oil yield is $34-37 \%$, but by conversion in alkali solution it decreases to $10-16 \%$.

Aliphatic hydrocarbons are represented by $n$-paraffins $\mathrm{C}_{12}-\mathrm{C}_{31}$ and isoprenoid compounds $i \mathrm{C}_{18}-i \mathrm{C}_{20}$. Polycyclic aromatic compounds are mainly represented by a series of naphtalene homologues; among neutral oxygen compounds methyl ketones and ketones with carbonyl group in the middle of the chain $\mathrm{C}_{11}-\mathrm{C}_{31}$ are identified. The ketones are formed not only by conversion in alkali solution as usual but also in liquefaction process.

The sulfur content decreases in oils obtained by thermal destruction in autoclave. especially by hydrogenation in comparison with semi-coking oil. 